\title{
Histórias e medialidades das exposições
}

Icaro Ferraz Vidal Junior'

I - Universidade de Tuiuti Curitiba (PR), Brasil

CYPRIANO, F.; OLIVEIRA, M. M. (Orgs.).

Histórias das exposições.

Casos exemplares.

São Paulo: EDUC, 2017. 176p.

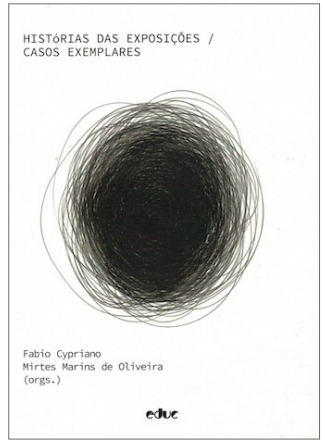

Resumo: A resenha percorre os argumentos centrais de Histórias das exposições. Casos exemplares, livro organizado por Fabio Cypriano e Mirtes Marins de Oliveira e aponta algumas articulações entre o emergente campo de estudos da História das Exposições e outras áreas de conhecimento.

Palavras-chave: história das exposições; curadoria; comunicação e artes.

Abstract: Histories and Medialities of Exhibitions - This review covers the central arguments of Histórias das exposições. Casos exemplares, edited by Cypriano and Oliveira and points out a few articulations between the emerging field of History of Exhibitions and other fields of knowledge.

Keywords: history of Exhibitions; curatorship; communication and arts.

Como integrar, na escrita da História da Arte, o contexto no qual os encontros do público com as obras de arte têm lugar? Histórias das exposições. Casos exemplares (CYPRIANO, OLIVEIRA, 2017) traz um inventário de problemáticas que recentemente ingressaram nos estudos curatoriais, um campo tão jovem quanto híbrido, mas que demonstra sua riqueza epistemológica ao inserir sistematicamente vetores como a espacialidade, o tempo, o corpo, os contextos histórico, político e institucional nas reflexões sobre arte.

Os organizadores Fabio Cypriano, crítico de arte, professor do Departamento de Jornalismo e coordenador do curso Arte: História, Crítica e Curadoria da PUC-SP, e Mirtes Marins de Oliveira, professora e pesquisadora no Programa de Pós-Graduação em 
Design da Universidade Anhembi Morumbi, adotam como ponto de partida uma diferença entre o campo da história da arte e o campo da história das exposições. Tal diferença é desenvolvida por Pablo Lafuente, curador espanhol que foi, entre 2010 e 2015, co-editor da revista Afterall ${ }^{1}$ e da série de livros Exhibition Histories, na entrevista que abre o livro: muitas vezes a melhor forma de se compreender uma obra de arte é no lugar e no tempo em que ela se torna pública e isso se dá, em geral, nas exposições. Daí derivam algumas questões metodológicas: o que analisar? O texto curatorial? O catálogo? Os registros visuais? Onde a recepção deixa seus rastros? Onde o contexto institucional manifesta suas matrizes ideológicas? Enquanto objeto de estudo, cada exposição contará com uma documentação específica, que o historiador das exposições deverá ser capaz de fazer falar.

Em seu artigo, Mirtes Marins de Oliveira adota o pressuposto de que um sistema de valores é instituído na própria materialidade do espaço expositivo e descreve a difusão do cubo branco como modelo expográfico hegemônico, a partir de uma série de ações do MoMA-NY, desde o final dos anos 1920. A controvérsia em torno desse dispositivo, cuja principal característica é a ausência de quaisquer ornamentos, está largamente vinculada a uma conscientização de que ele descontextualiza as relações históricas e sociais que atravessam as obras de arte.

Já Vinicius Pontes Spricigo, professor do Departamento de História da Arte da UNIFESP, empreende uma "escavação arqueológica", no sentido que atribui a Vilém Flusser, a fim de escapar ao privilégio euramericano na definição do corpus canônico de exposições, que acaba por circunscrever exposições ocorridas em países ditos "não-ocidentais" à perspectiva da arte global dos anos 1990. Sua crítica sinaliza que o campo da história das exposições, apesar dos avanços que promove ao considerar a esfera institucional de difusão da arte, não desestabiliza a hegemonia de instituições europeias e americanas.

Em movimento análogo ao de Spricigo, a pesquisadora e curadora Ana Maria Maia estuda dois projetos realizados no Brasil no início da década de 1970. Os Domingos da Criação do MAM-Rio e a $6^{2}$ Jovem Arte Contemporânea do MAC-USP foram projetos pioneiros no processo de "desmaterialização" da arte, que internacionalmente vinculou-se às críticas ao mercado, mas aqui também foi uma estratégia de esquiva à censura. A retomada dessas ações no âmbito da constituição de uma história das exposições no Brasil vem remediar o diagnóstico de Spricigo, consolidando um corpus brasileiro de experiências curatoriais que promoveram rupturas importantes nos modos de expor.

Fernando Oliva, curador, pesquisador e professor da FAAP, também parte do contexto ditatorial para refletir sobre a $3^{a}$ Bienal da Bahia, ocorrida em 2014. O projeto da $3^{\text {a }}$ Bienal escova à contrapelo a história da arte brasileira, evocando as duas primeiras edições da bienal, ocorridas em 1966 e 1968, tendo a $2^{a}$ edição sido censurada na manhã seguinte à sua abertura, sob a sombra do Al-5. O conceito de reencenação de Kierkegaard fornece o solo teórico a partir do qual as fricções entre

1 A Afterall é uma editora inglesa, fundada em 1998 na Central Saint Martins (University of Arts London), que foi pioneira no criação e na difusão de metodologias para o estudo das Histórias das Exposições. 
passado, presente e futuro são pensadas, em relação com os elementos materiais e discursivos da exposição de 2014.

Derrida, Foucault e Benjamin são alguns dos autores que dão sustentação ao artigo de Priscila Arantes, curadora do Paço das Artes, professora da PUC-SP e do Programa de Pós-Graduação em Design da Universidade Anhembi Morumbi, sobre os diálogos entre arquivo, curadoria e história das exposições. A pesquisadora retraça a problemática estético-política dos arquivos para, então, deter-se na análise de alguns projetos icônicos. Da Boite-en-valise (1935-1941), de Duchamp à exposição Archive fever: uses of document in Contemporary Art, de 2008, passando pelo Museu Imaginário de Malraux e pelo projeto Livro/Acervo, do qual a própria autora foi uma das curadoras, Arantes apresenta uma consistente cartografia da ativação expositiva de arquivos.

Cauê Alves, curador do MUBE, professor do Departamento de Arte da PUC-SP e coordenador do Curso de Artes Visuais da Belas Artes/SP, recupera as controvérsias desencadeadas pela exposição Projeto Construtivo Brasileiro na Arte, realizada em 1977, e analisa alguns discursos contemporâneos à mostra, com base nos quais pôde constatar a reativação da polaridade entre a produção "paulista" e a "carioca", que já se encontrava relativamente apaziguada em 1977. Nesse sentido, o autor corrobora a impossibilidade de pensarmos em obras de arte isoladas de seu contexto expositivo como objeto de estudo da História da Arte.

Por fim, Fabio Cypriano recupera a história da Bienal de São Paulo e destaca as mudanças implementadas por Lisette Lagnado no contexto da $27^{\mathrm{a}}$ Bienal, Como viver juntos. Algumas proposições da curadora chegam até nossos dias, apesar da $27^{\mathrm{a}}$ Bienal não ter recebido o devido crédito por parte da crítica internacional. Concebida a partir de um repertório conceitual herdado de Hélio Oiticica, as obras de arte na $27^{\text {a }}$ Bienal não estavam reduzidas à condição de ilustrações de um argumento a priori. A exposição foi mais um catalisador de processos criativos do que uma reunião de obras de arte préexistentes a serviço da transmissão de uma mensagem.

Icaro Ferraz Vidal Junior é bolsista de pós-doutorado PNPDCapes no Programa de Pós-Graduação em Comunicação e Linguagens da Universidade Tuiuti do Paraná e pesquisador do MediaLab UFRJ. É doutor em "Cultural Studies in Literary Interzones" pelas Université de Perpignan Via Domitia e Università degli studi di Bergamo e em Comunicação e Cultura pela Universidade Federal do Rio de Janeiro.

vidal.icaro@gmail.com

\section{Referências}

CYPRIANO, F.; OlIVEIRA, M. M. (Orgs.). Histórias das exposições. Casos exemplares. São Paulo: EDUC, 2017. 